\title{
ARTICLE
}

Received 22 Mar 2014 | Accepted 7 Jul 2014 | Published 2 Sep $2014 \quad$ DOI: 10.1038/ncomms5607

\section{Physical autocatalysis driven by a bond-forming thiol-ene reaction}

\author{
Andrew J. Bissette ${ }^{1}$, Barbara Odell ${ }^{1} \&$ Stephen P. Fletcher ${ }^{1}$
}

Autocatalysis has been extensively studied because it is central to the propagation of living systems. Chemical systems which self-reproduce like living cells would offer insight into principles underlying biology and its emergence from inanimate matter. Protocellular models feature a surfactant boundary, providing compartmentalization in the form of a micelle or vesicle and any model of the emergence of cellular life must account for the appearance, and evolution of, such boundaries. Here, we describe an autocatalytic system where two relatively simple components combine to form a more complex product. The reaction products aggregate into micelles that catalyse molecular self-reproduction. Study of the reaction kinetics and aggregation behaviour suggests a mechanism involving micelle-mediated physical autocatalysis and led to the rational design of a second-generation system. These reactions are driven by irreversible bond formation and provide a working model for the autocatalytic formation of protocells from the coupling of two simple molecular components.

\footnotetext{
${ }^{1}$ Chemistry Research Laboratory, Department of Chemistry, University of Oxford, 12 Mansfield Rd, Oxford OX1 3TA, UK. Correspondence and requests for materials should be addressed to S.T.P. (email: stephen.fletcher@chem.ox.ac.uk).
} 
$\mathrm{T}$ he development of chemical models of living cells is a major contemporary challenge that would find application in the field of synthetic biology ${ }^{1}$ and bear on questions about the origins and, the very definition of, life ${ }^{2,3}$. Several designs for artificial cells have been put forward ${ }^{4-8}$. A notable and representative design proposed by Szostak, Bartel and Luisi ${ }^{9}$ consists of 'the union of two fundamentally different kinds of replicating systems': a self-replicating genetic polymer encapsulated by and coupled to a self-reproducing membrane. Such a system, if realized, may serve as a useful model of the earliest life forms and could even be considered a living organism $^{10-13}$.

Simple chemical models of both self-replicating genetic molecules and self-reproducing membranes have been developed over the past 30 years. Given the wide interest in simple autocatalytic molecules ${ }^{14,15}$ and the significant influence of the RNA world hypothesis ${ }^{16}$, molecules capable of template-based self-replication have been studied for many years. This field has advanced to the point that there now exist candidate substrates for the genetic material of a protocell ${ }^{17}$, and it has been proposed that non-enzymatic chemical replication of RNA may even be possible ${ }^{18}$.

The self-reproduction of simple models of membranes, namely micelles and vesicles, has also been studied, most notably by Luisi and co-workers ${ }^{4}$. These systems represent crucial components of protocellular models and provide experimental support for 'lipid world' scenarios for the origins of life ${ }^{19}$, where catalytically active surfactant aggregates, dubbed lipozymes, act as prebiotic analogues of enzymes and under a form of selection promoted the emergence of life.

Several systems are known in which surfactant aggregates catalyse chemical reactions that yield fresh surfactant molecules and thereby drive their own reproduction ${ }^{14}$. These reactions are autocatalytic with respect to the micelle or vesicle, a process that has been referred to as physical autocatalysis ${ }^{20-22}$, where the term autocatalysis is used in a broad sense, to refer to product-induced increase in reaction rate ${ }^{4,14}$. In contrast to the template-based replication, the type of reactions known to drive physical autocatalysis are extremely limited ${ }^{14}$ and almost all known examples are driven by hydrolysis-mediated chemical bond cleavage $^{14}$. To the best of our knowledge, the only examples of physical autocatalysis driven by bond-forming processes involve simple $\mathrm{N}$-oxidation of an amine ${ }^{23}$, or imine condensation that is chemically reversible and operates under thermodynamic control $^{24,25}$ (Fig. 1).

A simple model protocell consists of 'core and shell' replication. Here, either a simple self-replicating molecule or an enzymatic system is encapsulated by a self-reproducing micelle $^{26,27}$ or vesicle 28,29 . Developing a chemical protocellular model system of this kind has been a research goal for several
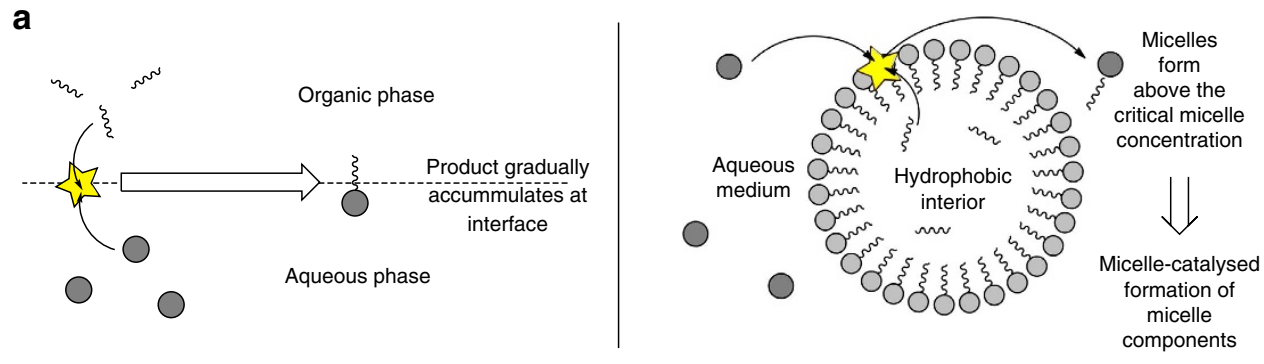

b

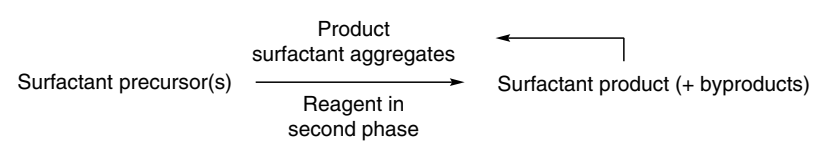

c

cond phase

d<smiles>CCCCCCCC(=O)OCC</smiles>
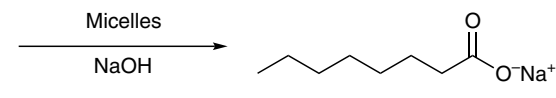<smiles>CCCCCCCCCCCCN(C)C</smiles>
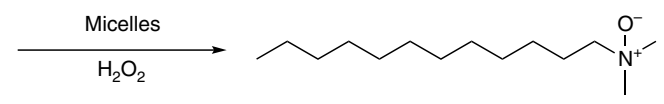

e

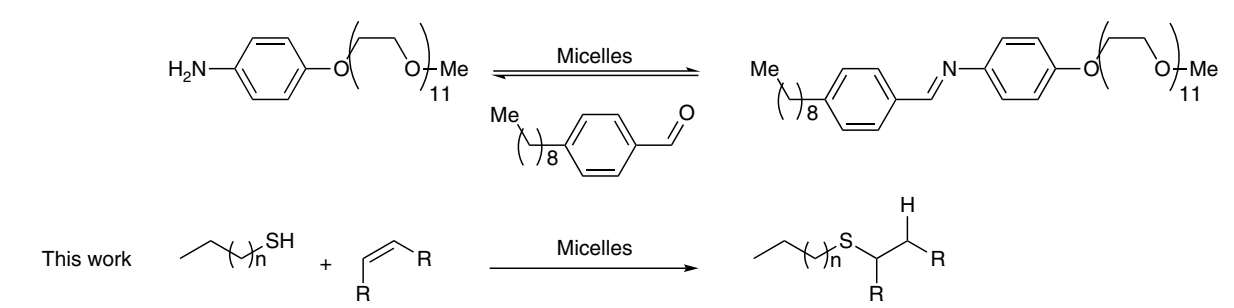

f

Figure 1 | Physical autocatalysis in micelles. (a) Schematic representation of physical autocatalysis. Species separated by a phase boundary react at the interface; the reaction is catalysed by the formation of product aggregates that allow species in each phase to mix. (b-e) Previous examples of physical autocatalysis can be divided into three classes of reaction, illustrated here with representative examples. Schemes are simplified to emphasize the reaction partners and the catalytically active product. (b) General principle of physical autocatalysis: a biphasic reaction generates surfactant products that autocatalyse the reaction; (c) Hydrolysis, typically of anhydrides, esters or imines (example from ref. 35); (d) Simple oxidation (example from ref. 23); (e) Reversible imine condensation under thermodynamic control (example from ref. 24); (f) This work, demonstrating physical autocatalysis in an irreversible bond-forming reaction. 


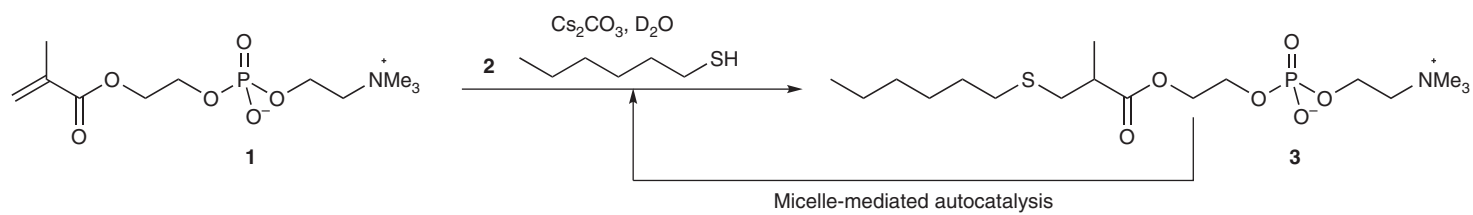

Figure 2 | Design of an autocatalytic model system based on a thiol-ene reaction. Substrates were previously reported by Matsuno et al. ${ }^{34}$ The biphasic reaction of $\mathbf{1}$ and $\mathbf{2}$ produces $\mathbf{3}$. As $\mathbf{3}$ forms micelles above $25 \mathrm{mM}$, it was expected to catalyse the reaction, and hence the reaction was predicted to be autocatalytic.

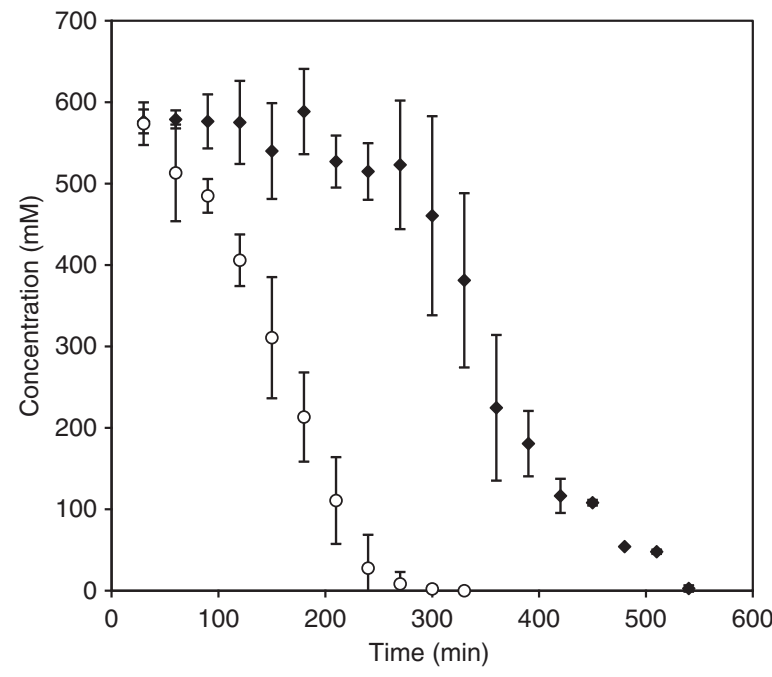

Figure 3 | Evidence of autocatalysis in the reaction of 1 and 2. The reaction is monitored by disappearance of $\mathbf{1}$ by ${ }^{1} \mathrm{H}$ NMR spectroscopy. Data points are the mean of three experiments and error bars show the s.d. - Control reaction: when $\mathbf{1}$ and $\mathbf{2}$ are stirred gently, a lag period followed by a faster reaction period is observed. $\bigcirc$ Seeded reaction: when the reaction is seeded with $\mathbf{3}$ at $t=0$, the lag period is eliminated and the reaction proceeds in a more linear fashion. Representative stacked spectra are shown in Supplementary Figs 6 and 7

decades; the state-of-the-art was recently and elegantly exemplified by Kurihara et al. ${ }^{30}$, who amplified DNA by the PCR within self-reproducing vesicles and demonstrated a coupling between the replication of nucleotides and lipids.

Given the wide interest in developing protocells, we set out to explore which classes of reactions are actually capable of driving physical autocatalysis. As a starting point, we reasoned that reactions that generate molecular complexity would, at least in principle, appear to be much more relevant to the transition of simple prebiotic building blocks into living systems. Bondforming autocatalytic systems would provide a model for the transition of simple molecules to more complex matter capable of catalytic function, as well as expand the tool kit available to protocell researchers. Synthetic reactions, where relatively simple components are brought together to make a more complex product, are arguably much more relevant to prebiotic synthesis than bond-cleaving or oxidation reactions and would allow the development of experimental tests of key claims of 'lipid world' scenarios. Here, by simple and complex, we are making a general observation about the molecular weight and functionality of molecules. Such reactions are a prerequisite for chemical studies of simple evolutionary processes such as selection and competition $^{24}$ analogous to the behaviour demonstrated in templatebased replicators by Rebek ${ }^{31}$, Von Kiedrowski ${ }^{32}$ and others ${ }^{14}$. Coupling processes are necessary for the combinatorial autocatalytic synthesis of a diverse population of lipids from a smaller number of precursors, whereas the use of hydrolysis reactions to generate new lipids imposes a hard limit on the number of potential lipid species in the system.

To these ends, we report here a novel example of physical autocatalysis driven by irreversible bond formation. Two thiol-ene reactions are described in which the coupling of molecules of very different polarities produces an amphiphilic product, which aggregates into autocatalytically active micelles. The phase behaviour of the reaction components is studied by diffusion-ordered NMR spectroscopy (DOSY), providing some insight into the mechanism of the reaction. These systems offer a chance for novel experimental tests of key claims of the lipid world hypothesis and expand the options available for the development of protocell models.

\section{Results}

Design of self-reproducing micelles. As a simple model system for complexity-generating physical autocatalytic reactions, we chose to study thiol-ene reactions ${ }^{33}$, the base-catalysed 1,4 -conjugate addition of thiols to $\alpha, \beta$-unsaturated carbonyls, as these are simple, selective and compatible with aqueous conditions. A candidate substrate based on a report by Matsuno et al. ${ }^{34}$ who synthesized a library of micelle-forming phospholipids, was identified. The phospholipid was made by coupling two reactants of very different polarity, to give a stable amphiphilic product, and was deemed to be an ideal test reaction to probe physical autocatalysis (Fig. 2).

Our initial approach to this system was intended to be as straightforward as possible. As such, we imitated the reaction conditions used by Bachmann et al. ${ }^{35}$ in their classic paper establishing physical autocatalysis in micelles: two clearly separated phases, stirred gently and monitored by removal of aliquots. Other authors studying physical autocatalysis have opted to rapidly mix the two phases to reduce the reaction time ${ }^{36}$; our choice was based on several considerations, particularly the desire to sample the aqueous phase directly and thereby minimize the amount of thiol present in the NMR tube to improve spectral quality.

After preliminary experimentation, we found that when a solution of 2-methacryloyloxyethyl phosphorylcholine $\mathbf{1}$ in $\mathrm{D}_{2} \mathrm{O}$ at high $\mathrm{pH}$ is gently stirred with hexanethiol 2, autocatalytic behaviour is observed (Fig. 3). The high $\mathrm{pD}$ of the reaction leads to rapid but self-limiting hydrolysis of $\mathbf{1}$ to methacrylate within the first minutes of the reaction (see Supplementary Figs 1-3). After about $20 \%$ hydrolysis, the Michael acceptor is stable to further degradation and autocatalytic 1,4-addition of 2 is then observed.

Autocatalysis in the conjugate addition is suggested by two observations characteristic of autocatalytic processes ${ }^{14}$. The first of these is an increase in the rate of the reaction following a lag period (Fig. 3, black circles). The second observation supporting the autocatalytic behaviour is that the reaction rate increases when $20 \mathrm{~mol} \%(130 \mathrm{mM}$, critical micelle concentration $(\mathrm{cmc})=25 \mathrm{mM}$ (ref. 34)) of the product is added at the start of the reaction (Fig. 3, white circles). This behaviour is reproducible (see Supplementary Fig. 4) and, consistent with the detailed 


\begin{tabular}{|c|c|c|c|}
\hline Species present & D (lipid 3) & D (thiol 2) & D (TMS) \\
\hline 2 (saturated) & - & 16 & - \\
\hline $3(5 \mathrm{mM})$ & 4.4 & - & - \\
\hline $3(100 \mathrm{mM})$ & 1.7 & - & - \\
\hline 2 (saturated) & 4.4 & 9.6 & - \\
\hline \multicolumn{4}{|l|}{$3(5 \mathrm{mM})$} \\
\hline 2 (saturated) & 1.5 & 1.0 & 0.95 \\
\hline \multicolumn{4}{|l|}{$3(100 \mathrm{mM})$} \\
\hline TMS (saturated) & & & \\
\hline
\end{tabular}

kinetic studies of related reactions ${ }^{36}$, sensitive to various physical factors including the size and orientation of the stirrer bar, the rate of stirring, and the shape of the reaction flask (see Supplementary Fig. 5).

The mechanism by which physical autocatalysis proceeds has been debated. Early work on self-reproducing micelles assumed that these reactions proceed through micellar catalysis, but this was disputed by Buhse et al. ${ }^{36,37}$ The latter developed kinetic models and concluded that physical autocatalysis can be thought of as a form of phase transfer catalysis. Essentially, the difference between the two models is in the location of the key reaction: Luisi et al. assumed that the reaction occurred at the micelle, while Buhse et al. provide evidence that the surfactant precursor is released from micelles into the aqueous phase to react in bulk solution.

NMR studies. We opted to use DOSY to study this reaction. This technique has been used to study the formation of micelles and uptake of solutes into micelles for several decades, and provides insight into aggregation phenomena by measuring the self-diffusion coefficient of molecules, which is strongly correlated with the average size and shape of a species or an aggregate $e^{38,39}$. Nguyen et al. ${ }^{24}$ used DOSY in their study of self-reproducing micelles but as their starting materials and product are in equilibrium, the concentrations of components cannot be adjusted independently. As the thiol-ene reaction described here is irreversible, we were able to take our DOSY study further and show how aggregation of individual reaction components varies with concentration.

Our first step was to confirm the $\mathrm{cmc}$ of $\mathbf{3}$ by DOSY. This was reported by Matsuno et al. to be $25 \mathrm{mM}$ as determined by surface tension measurements; by DOSY, we measure a $\mathrm{cmc}$ of $26.5 \mathrm{mM}$, in close agreement (see Supplementary Fig. 8). Following this we repeated the measurement in the presence of $2(100 \mathrm{mM})$ to see if mixed micelles of the thiol and lipid have a significantly lower $\mathrm{cmc}$. Under these conditions we measured a $\mathrm{cmc}$ of $23.4 \mathrm{mM}$, consistent with favourable formation of mixed micelles of $\mathbf{3}$ and $\mathbf{2}$ (ref. 36). It is clear from the diffusion coefficient $(D)$ values (Table 1) obtained for $\mathbf{2}$ in the presence and absence of $\mathbf{3}$ that, in the presence of micelles of 3,2 is significantly solubilized (Fig. 4). Using a method reported by Stilbs ${ }^{40}$, which uses tetramethylsilane (TMS) as a reporter molecule for micellar diffusion coefficient, we calculated the degree of solubilization of 2 into micelles of 3 $([3]=100 \mathrm{mM})$ as $>99 \%$. On this basis, we would tentatively like to conclude that our system largely operates by the micellar catalysis mechanism proposed by Luisi, rather than a phase transfer mechanism as described by Buhse et al. ${ }^{36}$

Unfortunately, the applicability of these results to our reaction conditions is not clear. The high $\mathrm{pH}$ of the reaction means that significant quantities of thiolate ion are present. These would be
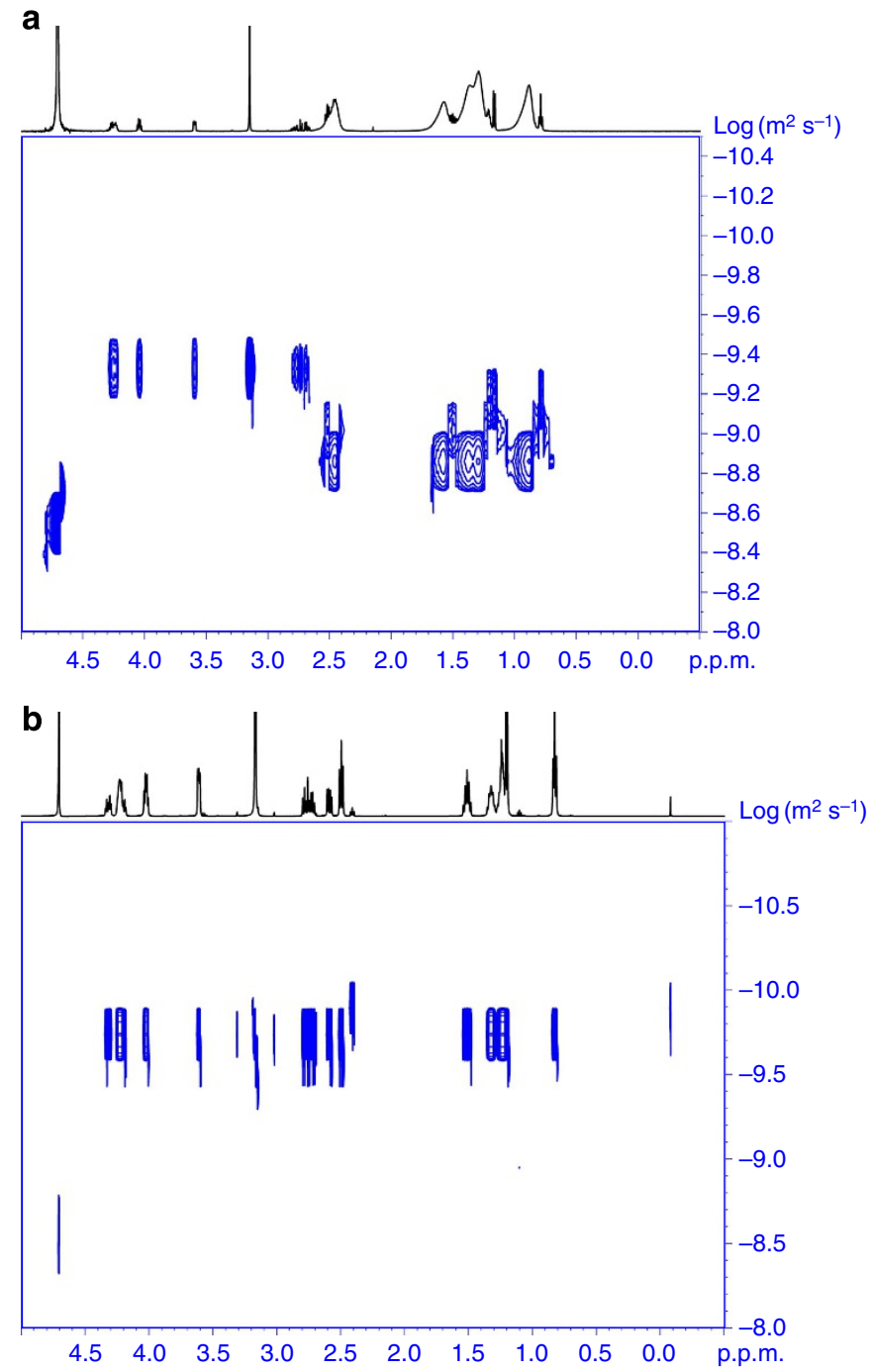

Figure 4 | DOSY NMR showing uptake of 2 into micelles of 3.

(a) 2D DOSY spectrum shows the difference in $D$ for $\mathbf{2}$ and $\mathbf{3}$. Peaks between 2.5-0.5 p.p.m. correspond to protons of $\mathbf{2}$ and the alkyl chain of $\mathbf{3}$, with an isolated triplet at 2.42 p.p.m. providing $D$ for $\mathbf{2}$. Experiment performed on a mixture of $\mathbf{3}$ (1 mM) and $\mathbf{2}$ (saturated); (b) 2D DOSY spectrum shows the coincidence of diffusion coefficients for $\mathbf{2}, \mathbf{3}$ and TMS. Experiment performed on a mixture of $\mathbf{3}(100 \mathrm{mM}), \mathbf{2}$ (saturated) and TMS (saturated). See also Supplementary Fig. 9.

expected to be significantly more soluble in water than the thiol and hence the degree of solubilization into the micelle may be lower. Further, the higher ionic strength due to the presence of $\mathrm{Cs}_{2} \mathrm{CO}_{3}$ may well affect the aggregation properties of $\mathbf{3}$. We opted not to repeat the DOSY study at high $\mathrm{pD}$ as any hydrolysis of $\mathbf{3}$ would affect the obtained diffusion coefficients, and the higher ionic strength of the solution gave poor spectral resolution in preliminary measurements, leading to overlap of peaks of $\mathbf{2}$ and 3 .

Design of a second-generation system. With these issues in mind, we decided to rationally design a second-generation system. We envisaged that a more reactive alkene would give higher levels of reactivity. This may allow reaction under milder conditions and/or at lower concentrations, and possibly allow the use of longer thiols, which we found were quite unreactive with the above system. Further, a reaction carried out at neutral $\mathrm{pH}$ would allow our DOSY study to be directly applicable to the reaction conditions. 


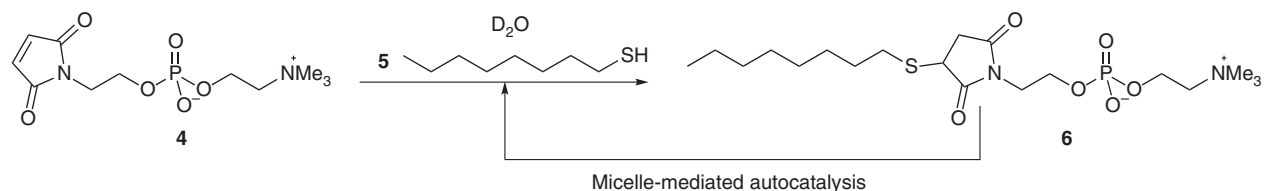

Figure 5 | Second-generation autocatalytic thiol-ene reaction. The biphasic reaction of $\mathbf{4}$ and $\mathbf{5}$ produces $\mathbf{6}$. As $\mathbf{6}$ forms micelles above $5 \mathrm{mM}$, it was expected to catalyse the reaction, and hence the reaction was predicted to be autocatalytic. The use of a maleimide as the Michael acceptor allows the reaction to proceed under conditions more relevant to model protocells.

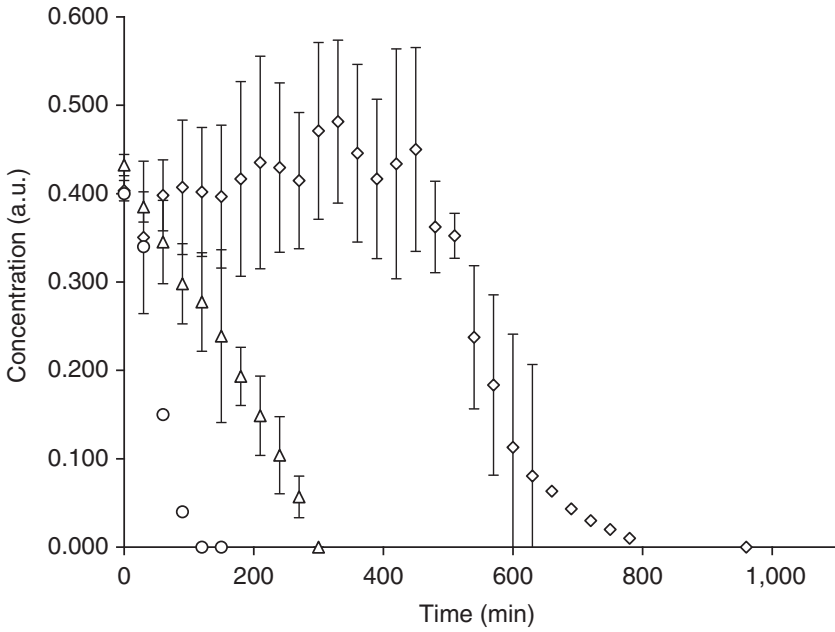

Figure 6 | Evidence of autocatalysis in the reaction of 4 and 5 . The reaction is monitored by disappearance of $\mathbf{4}$ by ${ }^{1} \mathrm{H}$ NMR spectroscopy. Data points are the mean of three experiments and error bars show the s.d. $\diamond$ Control reaction: when $\mathbf{4}$ and $\mathbf{5}$ are stirred gently, a lag period followed by a faster reaction period is observed. $\Delta$ Seeded reaction: when the reaction is seeded with $20 \mathrm{~mol} \% \mathbf{6}$ at $t=0$, the lag period is eliminated and the reaction proceeds linearly. $\bigcirc$ Seeded reaction (single experiment): addition of $70 \mathrm{~mol} \%$ of $\mathbf{6}$ at $t=0$ further increases the rate of reaction. Representative stacked spectra are shown in Supplementary Figs 10 and 11.

Lipid precursor 4 contains a maleimide, widely used in bioconjugation reactions ${ }^{41}$ (Fig. 5).

When a solution of maleimide 4 in $\mathrm{D}_{2} \mathrm{O}(21 \mathrm{mM}$ Tris buffer, $\mathrm{pD}$ 7.85) is gently stirred with octanethiol $\mathbf{5}$, autocatalytic behaviour is again observed (Fig. 6). The reaction was found to be sensitive to $\mathrm{pD}$; below 7 , the reaction hardly proceeds, and above pD 7.9 some $(\sim 5 \%)$ hydrolysis of the maleimide is observed. As before, autocatalysis is suggested by an increase in the rate of reaction following a lag period, and the elimination of this lag period by the addition of lipid $\mathbf{6}$ at the start of the reaction.

That the lag period is longer than in the above system is readily explained by the lower solubility of octanethiol in neutral $\mathrm{D}_{2} \mathrm{O}$ than hexanethiol in alkaline $\mathrm{D}_{2} \mathrm{O}$. However, on the formation of quantities of $\mathbf{6}$ in excess of its $\mathrm{cmc}$, the reaction proceeds at a similar rate to the first-generation system, reflecting the higher reactivity of the maleimide. The large s.d. of peaks in the linear reaction phase are an artefact of the fact that each reaction reaches this phase at a slightly different time; the raw data are plotted in the SI.

NMR studies of the second-generation system. The $\mathrm{cmc}$ of $\mathbf{6}$ was measured as $4.8 \mathrm{mM}$ by DOSY NMR (see Supplementary Fig. 8). As before, the study of the maleimide-based system by DOSY NMR (Fig. 7) clearly shows that $\mathbf{5}$ is entirely bound within 6 when $\mathbf{6}$ is present in a large excess of its $\mathrm{cmc}$ (Table 2). In this

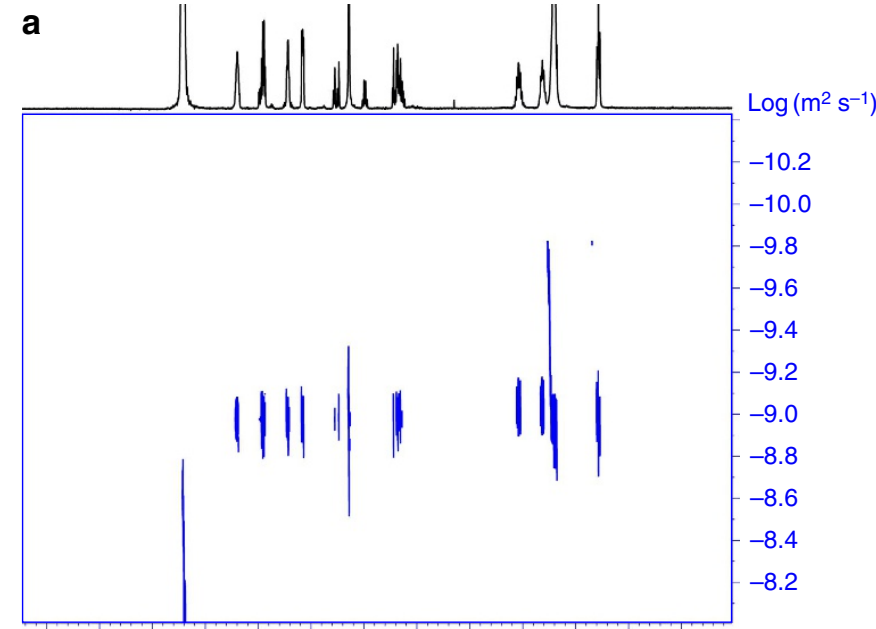

$\begin{array}{llllllllllllll}6.0 & 5.5 & 5.0 & 4.5 & 4.0 & 3.5 & 3.0 & 2.5 & 2.0 & 1.5 & 1.0 & 0.5 & 0.0 & \text { p.p.m. }\end{array}$

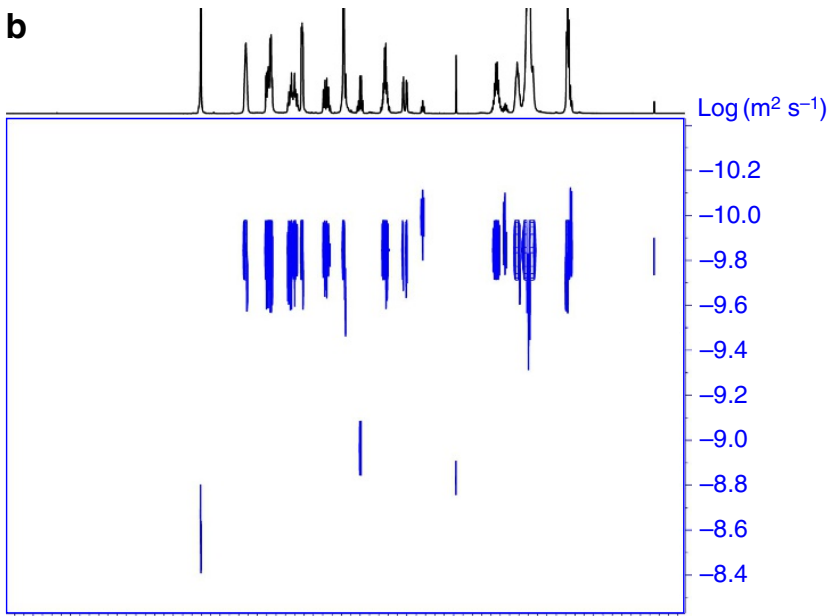

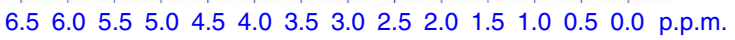

Figure 7 | DOSY NMR showing uptake of 5 into micelles of 6.

(a) 2D DOSY spectrum shows rapid diffusion of $\mathbf{6}$. No $\mathbf{5}$ was directly observed in this experiment despite the solution being saturated before measurement. Experiment performed on a mixture of $\mathbf{6}(2 \mathrm{mM})$ and $\mathbf{5}$ (saturated; corresponding to Table 2 row D); (b) 2D DOSY spectrum shows the coincidence of diffusion coefficients for 5, $\mathbf{6}$ and TMS. Experiment performed on a mixture of $\mathbf{6}(50 \mathrm{mM}), \mathbf{2}$ (saturated) and TMS (saturated; corresponding to Table 2 row H). See also Supplementary Fig. 12.

case, we studied the aggregation behaviour at a greater range of concentrations, and confirmed that the maleimide starting material $\mathbf{4}$ neither aggregates nor is taken into the micelles of $\mathbf{6}$ (Table 2, rows I-K).

In the presence of sub-cmc concentrations of $\mathbf{6}$, thiol $\mathbf{5}$ is not readily detectible by ${ }^{1} \mathrm{H}$ NMR (Table 2 , row $\mathrm{D}$ ); trace quantities were seen in the two-dimensional (2D) DOSY spectrum but 


\begin{tabular}{|c|c|c|c|c|c|}
\hline Entry & Species present & $\begin{array}{c}D \\
\text { (lipid 6) }\end{array}$ & $\begin{array}{c}D \\
\text { (thiol 5) }\end{array}$ & $\begin{array}{c}D \\
\text { (TMS) }\end{array}$ & $\begin{array}{c}D \\
\text { (alkene 4) }\end{array}$ \\
\hline A & 5 (saturated) & - & 9.6 & - & - \\
\hline B & $6(2 \mathrm{mM})$ & 4.0 & - & - & - \\
\hline C & $6(50 \mathrm{mM})$ & 1.2 & - & - & - \\
\hline D & $\begin{array}{l}\mathbf{5} \text { (saturated) } \\
\mathbf{6}(2 \mathrm{mM})\end{array}$ & 3.8 & $\begin{array}{c}\text { Not } \\
\text { detected }\end{array}$ & - & - \\
\hline $\mathbf{E}$ & $\begin{array}{l}5 \text { (saturated) } \\
\mathbf{6}(5 \mathrm{mM}) \\
\text { TMS (saturated) }\end{array}$ & 3.3 & 12 & 3.5 & - \\
\hline $\mathbf{F}$ & $\begin{array}{l}5 \text { (saturated) } \\
\mathbf{6}(10 \mathrm{mM}) \\
\text { TMS (saturated) }\end{array}$ & 2.8 & 1.2 & 2.3 & - \\
\hline G & $\begin{array}{l}5 \text { (saturated) } \\
\mathbf{6}(20 \mathrm{mM}) \\
\text { TMS (saturated) }\end{array}$ & 1.9 & 0.77 & 2.1 & - \\
\hline H & $\begin{array}{l}5 \text { (saturated) } \\
\mathbf{6}(50 \mathrm{mM}) \\
\text { TMS (saturated) }\end{array}$ & 1.1 & 0.64 & 1.06 & - \\
\hline I & $4(100 \mathrm{mM})$ & - & - & - & 5.0 \\
\hline J & $\begin{array}{l}\mathbf{4}(100 \mathrm{mM}) \\
\mathbf{6}(3 \mathrm{mM})\end{array}$ & 3.8 & - & - & 4.6 \\
\hline $\mathbf{K}$ & $\begin{array}{l}4(100 \mathrm{mM}) \\
\mathbf{6}(50 \mathrm{mM})\end{array}$ & 1.3 & - & - & 4.6 \\
\hline \multicolumn{6}{|c|}{$\begin{array}{l}\text { TMS, tetramethylsilane. } \\
\text { The diffusion coefficient }(D) \text { of } \mathbf{5} \text { decreases significantly in the presence of } \mathbf{6} \text { when } \mathbf{6} \text { is above its } \\
\text { cmc }(4.8 \mathrm{mM}) \text {, indicating the formation of mixed micelles of } \mathbf{5} \text { and } \mathbf{6} \text {. } \\
\text { TMS is seen to have a higher } D \text { than } \mathbf{5} \text {, suggesting slight solubility of TMS in water and } \\
\text { quantitative binding of } \mathbf{5} \text { to } 6 \text {. D values reported in } 10^{-10} \mathrm{~m}^{2} \mathrm{~s}^{-1} \text {. No interaction between polar } \\
\text { maleimide } \mathbf{4} \text { and micelles of } \mathbf{6} \text { is observed. 2D DOSY NMR spectra for key experiments can be } \\
\text { seen in Supplementary Fig. 13. }\end{array}$} \\
\hline
\end{tabular}

diffusion coefficients could not be obtained from these data. This decrease in solubility in the presence of $\mathbf{6}$ compared to a solution of pure $\mathbf{5}$ may be due to a salting-out effect.

In the presence of $50 \mathrm{mM} 6(\sim 10$ times the cmc; Table 2, row $\mathrm{H}) \mathbf{5}$ is completely bound to slow-diffusing aggregates. Unexpectedly, under these conditions, 5 was found to have a lower $D$ than that of TMS. The Stilbs method ${ }^{40}$ assumes that TMS is fully bound to micelles and hence takes its $D$ as an approximation of the ideal diffusion of micelles, as the observed diffusion coefficient of lipids is an average of the free and aggregated lipid. In the case of lipid $\mathbf{6}$, thiol $\mathbf{5}$ was found to have an even smaller diffusion coefficient than TMS. These experiments strongly suggest that $\mathbf{5}$ is completely bound to micelles of $\mathbf{6}$, that is, all 5 is either in a bulk thiol layer or contained within micelles.

Despite this limitation, we studied the uptake of thiol at intermediate concentrations at and above the $\mathrm{cmc}$ (Table 2, rows E-G). As can be seen from Table 2, in the cmc region (5-10 mM), there is an appreciable concentration of free lipid compared with experiments at higher lipid concentrations, but the thiol is strongly bound even at a small excess of the cmc.

We therefore conclude that this reaction is unlikely to proceed via a phase transfer mechanism as described by Buhse et al. ${ }^{36}$ Thiol $\mathbf{5}$ is negligibly soluble in aqueous solution and as the concentration of lipid 6 increases beyond the $\mathrm{cmc}$, the diffusion coefficient of $\mathbf{5}$ continues to decrease as it binds tightly to growing micelles of $\mathbf{6}$. This suggests that the reaction occurs in association with the micelles, matching closely the mechanism proposed by Luisi and Varela ${ }^{42}$.

\section{Discussion}

The first studies of self-reproducing micelles reported by Luisi were an explicit attempt to develop a minimal autopoietic system. Autopoiesis is a definition of the minimal criteria for life originally proposed by Maturana and Varela ${ }^{43}$ describing a system, defined by a boundary, that encapsulates all of the processes needed to produce all of the components of the system $^{12}$. This system is also a minimal model of autopoiesis, consisting of one component (lipid 6) that forms a boundary encapsulating the reaction that generates 6 . Whether or not minimal autopoietic systems actually meet the minimal criteria for life is disputed even by proponents of autopoiesis ${ }^{2,12}$.

'Lipid world' scenarios of the origins of life have been assessed extensively in silico ${ }^{44}$ but experimental support remains limited. The use of coupling reactions to generate new lipids irreversibly provides the conceptual basis for experimental tests of 'lipid world' models by allowing the combinatorial synthesis of heterogeneous populations of lipid assemblies. Diverse lipid populations of this kind are prerequisites for models of competition and selection amongst physical autocatalysts relevant to the origins of life. As such, the novel reactions reported here may allow experimental testing of proposed prebiotic chemistry.

In summary, we have described two examples of physical autocatalysis driven by thiol-ene chemistry. These are the first examples of physical autocatalysis driven by irreversible bond formation and as such represent both a novel technology for the study of model protocells and a model for the autocatalytic generation of functional complex molecules under prebiotic conditions. We anticipate autocatalytic coupling reactions will aid new experimental models of prebiotic chemistry and in the development of model protocells.

\section{Methods}

General experimental. All chemicals and solvents were purchased from Sigma Aldrich or Apollo Scientific and used without further purification.

All NMR spectra were recorded at room temperature. NMR spectra were recorded using Bruker DPX-200 (200 MHz), DPX-250 (250 MHz), DRX-500 $(500 \mathrm{MHz})$ or AVC-500 $(500 \mathrm{MHz})$ spectrometers. ${ }^{13} \mathrm{C}$ and ${ }^{31} \mathrm{P}$ NMR spectra were recorded using Bruker AVC-500 (500/125 MHz) and DRX-500 (500/200 Mhz) spectrometers, respectively. Chemical shifts are reported in p.p.m. from the residual solvent peak. Chemical shifts $(\delta)$ are given in p.p.m. and coupling constants $(J)$ are quoted in hertz $(\mathrm{Hz})$. Resonances are described as s (singlet), d (doublet), t (triplet), $\mathrm{q}$ (quartet) and $\mathrm{m}$ (multiplet).

High-resolution mass spectra were recorded using a Bruker MicroTOF spectrometer by the internal service at the University of Oxford.

${ }^{1} \mathrm{H}$ NMR spectra of key reagents can be seen in Supplementary Figs 14-17

$\mathrm{pD}$ measurements of samples in $\mathrm{D}_{2} \mathrm{O}$ were made using a Jenway $3510 \mathrm{pH}$ meter calibrated using standard reference samples in $\mathrm{H}_{2} \mathrm{O}$. pD values were estimated from the observed $\mathrm{pH}^{*}$ values according to Krężel and $\mathrm{Bal}^{45}$.

DOSY NMR measurements were performed using a Bruker AVII-500 equipped with a TFI probehead at $298 \mathrm{~K}$ using the $2 \mathrm{D}$ sequence for diffusion measurement using double stimulated echo for convection compensation and longitudinal eddy current delay, using bipolar gradient pulses for diffusion, and using three spoil gradients (Bruker terminology: dstebpgp35) pulse sequence ${ }^{46,47}$. The samples were thoroughly mixed using a Vortex Genie 2 mixer (Scientific Industries), and were then clarified using a hand centrifuge (Hettich, model 1011) and then measured. Samples containing saturated thiol consequently had a small layer of neat thiol above the $\mathrm{D}_{2} \mathrm{O}$ layer; sufficient $\mathrm{D}_{2} \mathrm{O}$ was used to ensure that the thiol layer was not detectible by the NMR probe. Experiments were performed in two stages: initially $1 D$-edited DOSY experiments were used to optimize the diffusion period $\Delta$ for each of $3(\Delta=150 \mathrm{~ms})$ and $\mathbf{6}(\Delta=170 \mathrm{~ms})$. The $2 \mathrm{D}$ dstebpgp35 sequence was then used, based on the optimized $\Delta$ from the previous procedure and with $\delta=4 \mathrm{~ms}$, with gradient amplitude ranging from 2 to $85 \%$ with 16 points in between. Data were analysed using the T1T2 module in TOPSPIN 3.2 and plots were generated using the eddosy module.

Synthesis of compound 3. Compound $\mathbf{3}$ was synthesized according to Matsuno et l. $^{34}$ From $1(2.50 \mathrm{~g}, 8.47 \mathrm{mmol})$ and $2(1.30 \mathrm{ml}, 9.15 \mathrm{mmol}, 1.08 \mathrm{eq})$ in EtOH $(10 \mathrm{ml})$ was obtained pure $3(2.45 \mathrm{~g}, 5.92 \mathrm{mmol}, 70 \%) .{ }^{1} \mathrm{H}$ NMR $(500 \mathrm{MHz}$, $\left.\mathrm{CD}_{3} \mathrm{OD}\right) \delta 4.20-4.36(\mathrm{~m}, 4 \mathrm{H}), 4.08(\mathrm{dt}, J=7.0,4.9 \mathrm{~Hz}, 2 \mathrm{H}), 3.60-3.69(\mathrm{~m}, 2 \mathrm{H})$, $3.24(\mathrm{~s}, 9 \mathrm{H}), 2.80$ (dd, $J=13.7,7.4 \mathrm{~Hz}, 1 \mathrm{H}), 2.71$ (ddq, $J=13.7,12.8,7.0,7.0$, $7.0 \mathrm{~Hz}, 1 \mathrm{H}), 2.60(\mathrm{dd}, J=12.9,6.3 \mathrm{~Hz}, 1 \mathrm{H}), 2.53(\mathrm{t}, J=7.3 \mathrm{~Hz}, 2 \mathrm{H}), 1.56$ (quin, $J=7.4 \mathrm{~Hz}, 2 \mathrm{H}), 1.26-1.45(\mathrm{~m}, 6 \mathrm{H}), 1.24(\mathrm{~d}, J=6.9 \mathrm{~Hz}, 3 \mathrm{H}), 0.91(\mathrm{t}, J=7.0 \mathrm{~Hz}, 3$ $\mathrm{H}) ;{ }^{13} \mathrm{C}$ NMR $\left(125 \mathrm{MHz}, \mathrm{CD}_{3} \mathrm{OD}\right) \delta 176.86,67.49(\mathrm{dt}, J=7.4,3.1 \mathrm{~Hz}), 65.26$ $(\mathrm{d}, J=7.9 \mathrm{~Hz}), 64.71(\mathrm{~d}, J=5.5 \mathrm{~Hz}), 60.47(\mathrm{~d}, J=5.0 \mathrm{~Hz}), 54.76(\mathrm{t}, J=3.8 \mathrm{~Hz}, 3 \mathrm{C})$ $41.63,36.31,33.44,32.62,30.74,29.57,23.68,17.25,14.45 ;{ }^{31} \mathrm{P}$ NMR $(200 \mathrm{MHz}$, 
$\left.\mathrm{CD}_{3} \mathrm{OD}\right) \delta$ p.p.m. 0.81; high-resolution mass spectrometry electrospray ionization (HRMS (ESI)) $m / z$ calcd for $\mathrm{C}_{17} \mathrm{H}_{36} \mathrm{NNaO}_{6} \mathrm{PS}[\mathrm{M}+\mathrm{Na}]^{+}: 436.1893$, found: 436.1892 .

Synthesis of compound 4. $\mathrm{N}$-Hydroxyethyl maleimide was synthesized according to Heath et al. ${ }^{48}$ From maleic anhydride $(40.0 \mathrm{~g}, 407.9 \mathrm{mmol})$ was obtained pure $\mathrm{N}$-hydroxyethyl maleimide $(8.34 \mathrm{~g}, 59.1 \mathrm{mmol}, 14.5 \%$ yield over three steps). ${ }^{1} \mathrm{H}$ NMR $\left(400 \mathrm{MHz},\left(\mathrm{CD}_{3}\right)_{2} \mathrm{SO}\right) \delta 7.01(\mathrm{~s}, 2 \mathrm{H}), 4.79(\mathrm{~m}, 1 \mathrm{H}), 3.46(\mathrm{~m}, 4 \mathrm{H})$; ${ }^{13} \mathrm{C}$ NMR $\left(101 \mathrm{MHz},\left(\mathrm{CD}_{3}\right)_{2} \mathrm{SO}\right) \delta 171.1,134.5,75.0,57.9$; MS (ESI) $\mathrm{m} / z 164.1$ $[\mathrm{M}+\mathrm{Na}]^{+}$. A solution of $\mathrm{N}$-hydroxyethyl maleimide $(4.30 \mathrm{~g}, 30.5 \mathrm{mmol})$ and triethylamine $(6.4 \mathrm{ml}, 45.7 \mathrm{mmol}, 1.5 \mathrm{eq})$ in dry tetrahydrofuran $(200 \mathrm{ml})$ was cooled to $0^{\circ} \mathrm{C}$ and 2-chloro-1,3,2-dioxaphospholane 2-oxide $(3.2 \mathrm{ml}, 33.5 \mathrm{mmol}$, $1.1 \mathrm{eq})$ was added dropwise. The reaction was allowed to warm to room temperature and to react until complete consumption of starting material (TLC control, EtOAc). The reaction mixture was filtered through $\mathrm{SiO}_{2}$ (eluting with EtOAc) and concentrated to a solid white residue. The crude solid was added under Ar to a $100 \mathrm{ml}$ pressure tube containing a stirrer bar and dry $\mathrm{MeCN}(80 \mathrm{ml})$ was added. The tube was cooled to $-20^{\circ} \mathrm{C}$ and freshly distilled $\mathrm{NMe}_{3}$ (2 ml, excess), stored at $-78^{\circ} \mathrm{C}$, was added. The tube was quickly sealed and then heated to $80^{\circ} \mathrm{C}$ overnight. On cooling to room temperature, the $\mathrm{MeCN}$ was decanted and a red precipitate, crude 4 , was purified by two rounds of $\mathrm{SiO}_{2}$ column chromatography in EtOAc/MeOH/ $\mathrm{H}_{2} \mathrm{O} / \mathrm{AcOH}(8: 8: 3: 1)$ and $\mathrm{MeCN} / \mathrm{H}_{2} \mathrm{O}(7: 3)$, respectively to give pure $4(2.8 \mathrm{~g}, 30 \%) .{ }^{1} \mathrm{H}$ NMR $\left(700 \mathrm{MHz}, \mathrm{CD}_{3} \mathrm{OD}\right) \delta 6.83(\mathrm{~s}, 2 \mathrm{H}), 4.24(\mathrm{~m}, 2 \mathrm{H})$, $4.01(\mathrm{dt}, J=6.2,5.6 \mathrm{~Hz}, 2 \mathrm{H}), 3.74(\mathrm{t}, J=5.7 \mathrm{~Hz}, 2 \mathrm{H}), 3.63(\mathrm{~m}, 2 \mathrm{H}), 3.22(\mathrm{~s}, 9 \mathrm{H})$; ${ }^{13} \mathrm{C}$ NMR $\left(176 \mathrm{MHz}, \mathrm{CD}_{3} \mathrm{OD}\right) \delta 172.6,135.3(\mathrm{~m}), 67.6(\mathrm{~m}), 63.6(\mathrm{~d}, J=5.1 \mathrm{~Hz})$, $60.6(\mathrm{~d}, J=5.1 \mathrm{~Hz}), 54.8(\mathrm{~m}), 39.5(\mathrm{~d}, J=7.9 \mathrm{~Hz}) ;{ }^{31} \mathrm{P}$ NMR $\left(202 \mathrm{MHz}, \mathrm{CD}_{3} \mathrm{OD}\right) \delta$ 0.94; HRMS (ESI) $m / z$ calcd for $\mathrm{C}_{11} \mathrm{H}_{19} \mathrm{~N}_{2} \mathrm{NaO}_{6} \mathrm{P}[\mathrm{M}+\mathrm{Na}]^{+}: 329.0873$, found: 329.0868 .

Synthesis of compound 6. Compund $4(500 \mathrm{mg}, 1.6 \mathrm{mmol})$ and octanethiol 5 $(0.32 \mathrm{ml}, 1.8 \mathrm{mmol}, 1.1 \mathrm{eq})$ were dissolved in $\mathrm{EtOH}(10 \mathrm{ml})$ and diisopropylamine (catalytic) was added. The reaction was stirred at room temperature until complete consumption of 4 (TLC control, $\mathrm{MeCN} / \mathrm{H}_{2} \mathrm{O}$ 7:3). The solvent was evaporated and the residue washed with hexane $(3 \times 10 \mathrm{ml})$ and then freeze-dried to give pure 6 (701 mg, 95.9\%). ${ }^{1} \mathrm{H}$ NMR $\left(700 \mathrm{MHz}, \mathrm{D}_{2} \mathrm{O}\right) \delta 4.25$ (br m, $2 \mathrm{H}$ ), 4.03 (dd, $J=9.0$, $4.1 \mathrm{~Hz}, 1 \mathrm{H}), 4.00(\mathrm{q}, J=5.7 \mathrm{~Hz}, 2 \mathrm{H}), 3.77(\mathrm{~m}, 2 \mathrm{H}), 3.63(\mathrm{~m}, 2 \mathrm{H}), 3.31(\mathrm{dd}$, $J=18.9,8.9 \mathrm{~Hz}, 1 \mathrm{H}), 3.19(\mathrm{~s}, 9 \mathrm{H}) 2.72(\mathrm{~m}, 3 \mathrm{H}), 1.59(\mathrm{dq}, J=13.8,7.0 \mathrm{~Hz}, 2 \mathrm{H})$, $1.36(\mathrm{~m}, 2 \mathrm{H}), 1.18-1.32(\mathrm{~m}, 8 \mathrm{H}), 0.83(\mathrm{t}, J=6.88 \mathrm{~Hz}, 3 \mathrm{H}) ;{ }^{13} \mathrm{C}$ NMR $(176 \mathrm{MHz}$, $\left.\mathrm{D}_{2} \mathrm{O}\right) \delta 179.7,178.3,66.0(\mathrm{~m}), 61.9(\mathrm{~d}, J=5.1 \mathrm{~Hz}), 59.5(\mathrm{~d}, J=5.1 \mathrm{~Hz}), 54.0$ $(\mathrm{t}, J=4.1 \mathrm{~Hz}), 40.1,39.6(\mathrm{~d}, J=7.6 \mathrm{~Hz}, 9 \mathrm{C}), 36.2,31.1,30.6,28.4,28.3,28.2$, $27.8,22.0,13.4 ;{ }^{31} \mathrm{P}$ NMR $\left(202 \mathrm{MHz}, \mathrm{D}_{2} \mathrm{O}\right) \delta 0.88$; HRMS (ESI) $\mathrm{m} / z$ calcd for $\mathrm{C}_{19} \mathrm{H}_{37} \mathrm{~N}_{2} \mathrm{NaO}_{6} \mathrm{PS}[\mathrm{M}+\mathrm{Na}]^{+}: 475.2002$, found: 475.2011 .

Autocatalytic reaction of 1 and 2. A stock solution of $1(680 \mathrm{mM}), \mathrm{Cs}_{2} \mathrm{CO}_{3}$ $(200 \mathrm{mM}), \mathrm{MeCN}(100 \mathrm{mM}, 0.15 \mathrm{eq})$ and optionally $3(134 \mathrm{mM}, 0.2 \mathrm{eq},>5 \times \mathrm{cmc})$ in $\mathrm{D}_{2} \mathrm{O}$ was prepared and allowed to stand for $5 \mathrm{~min}$. It was then divided into $2 \mathrm{ml}$ portions in cylindrical $20 \times 70 \mathrm{~mm}$ vials with octagonal $15 \times 5 \mathrm{~mm}$ magnetic stirrer bars. 1-Hexanethiol $3(1.9 \mathrm{ml}, 13.6 \mathrm{mmol}, 10 \mathrm{eq})$ was added to each vial by ejection from a syringe down the side of the vial so as not to disturb the aqueous layer. The biphasic mixture was stirred at 150 r.p.m. as determined by the digital readout of an IKA Basic stirrer/hotplate. Aliquots $(0.05 \mathrm{ml})$ were withdrawn from the aqueous layer and quenched by dilution with $0.6 \mathrm{ml} \mathrm{D}_{2} \mathrm{O}$, and analysed by ${ }^{1} \mathrm{H} \mathrm{NMR}$ spectroscopy on a 250 or $200 \mathrm{MHz}$ machine. Peaks were integrated relative to $\mathrm{MeCN}$ (2.06 p.p.m.).

Autocatalytic reaction of 4 and 5. A stock solution of $4(100 \mathrm{mM}), \mathrm{MeCN}$ $(100 \mathrm{mM})$ and optionally $6(20$ or $70 \mathrm{mM})$ in buffered $(21 \mathrm{mM}$ Tris, pD 7.85$) \mathrm{D}_{2} \mathrm{O}$ was prepared. It was then divided into $3 \mathrm{ml}$ portions in cylindrical $20 \times 70 \mathrm{~mm}$ vials with octagonal $15 \times 5 \mathrm{~mm}$ magnetic stirrer bars. 1-Octanethiol $5(0.53 \mathrm{ml}, 10 \mathrm{eq})$ was added to each vial by ejection from a syringe down the side of the vial so as not to disturb the aqueous layer. The biphasic mixture was stirred at 150 r.p.m. as determined by the digital readout of an IKA Basic stirrer/hotplate. Aliquots $(0.05 \mathrm{ml})$ were withdrawn from the aqueous layer and quenched by dilution with $0.6 \mathrm{ml} \mathrm{D}_{2} \mathrm{O}$ and analysed by ${ }^{1} \mathrm{H}$ NMR spectroscopy on a $400 \mathrm{MHz}$ machine. Peaks were integrated relative to $\mathrm{MeCN}$ (2.06 p.p.m.).

\section{References}

1. Jewett, M. C. et al. Semi-synthetic minimal cells: origin and recent developments. Curr. Opin. Biotechnol. 24, 633-638 (2013).

2. Mann, S. Systems of creation: the emergence of life from nonliving matter. Acc. Chem. Res. 45, 2131-2141 (2012).

3. Benner, S. A. Defining life. Astrobiology 10, 1021-1030 (2010).

4. Stano, P. \& Luisi, P. L. Achievements and open questions in the selfreproduction of vesicles and synthetic minimal cells. Chem. Commun. 46, 3639-3653 (2010).

5. Dzieciol, A. J. \& Mann, S. Designs for life: protocell models in the laboratory. Chem. Soc. Rev. 41, 79-85 (2012).
6. Cooper, G. J. T. et al. Modular redox-active inorganic chemical cells: iCHELLs. Angew. Chem. Int. Ed. Engl. 50, 10373-10376 (2011).

7. Hanczyc, M. M. Metabolism and motility in prebiotic structures. Philos. Trans. R. Soc. Lond. B. Biol. Sci. 366, 2885-2893 (2011).

8. Ganti, T. The Principles of Life 201 (Oxford University Press, 2003).

9. Szostak, J. W., Bartel, D. P. \& Luisi, P. L. Synthesizing life. Nature 409, 387-390 (2001).

10. Ruiz-Mirazo, K., Briones, C. \& de la Escosura, A. Prebiotic systems chemistry: new perspectives for the origins of life. Chem. Rev. 114, 285-366 (2014).

11. Wieczorek, R. On prebiotic ecology, supramolecular selection and autopoiesis. Orig. Life Evol. Biosph. 42, 445-450 (2012).

12. Luisi, P. L. Autopoiesis: a review and a reappraisal. Naturwissenschaften $\mathbf{9 0}$, 49-59 (2003)

13. Fleischaker, G. R. Origins of life: an operational definition. Orig. Life Evol. Biosph. 20, 127-137 (1990).

14. Bissette, A. J. \& Fletcher, S. P. Mechanisms of autocatalysis. Angew. Chem. Int. Ed. 52, 12800-12826 (2013).

15. Vidonne, A. \& Philp, D. Making molecules make themselves-the chemistry of artificial replicators. Eur. J. Org. Chem. 593-610 (2009).

16. Robertson, M. P. \& Joyce, G. F. The origins of the RNA world. Cold Spring Harb. Perspect. Biol. 4 (2012).

17. Zhang, S., Blain, J. C., Zielinska, D., Gryaznov, S. M. \& Szostak, J. W. Fast and accurate nonenzymatic copying of an RNA-like synthetic genetic polymer. Proc. Natl Acad. Sci. USA 110, 17732-17737 (2013).

18. Szostak, J. W. The eightfold path to non-enzymatic RNA replication. J. Syst. Chem. 3, 2 (2012).

19. Segré, D., Ben-Eli, D., Deamer, D. W. \& Lancet, D. The lipid world. Orig. Life Evol. Biosph. 31, 119-145 (2001).

20. Dyson, F. Origins of Life (Cambridge University Press, 1985).

21. Luisi, P. L. Emergence of Life: From Chemical Origins to Synthetic Biology (Cambridge University Press, 2006).

22. Wintner, E. A., Conn, M. M. \& Rebek, J. Studies in molecular replication. Acc. Chem. Res. 27, 198-203 (1994).

23. Kust, P. R. \& Rathman, J. F. Synthesis of surfactants by micellar autocatalysisN,N-dimethyldodecylamine N-oxide. Langmuir 11, 3007-3012 (1995).

24. Nguyen, R., Allouche, L., Buhler, E. \& Giuseppone, N. Dynamic combinatorial evolution within self-replicating supramolecular assemblies. Angew. Chem. Int Ed. 48, 1093-1096 (2009).

25. Takakura, K., Toyota, T. \& Sugawara, T. A novel system of self-reproducing giant vesicles. J. Am. Chem. Soc. 125, 8134-8140 (2003).

26. Bohler, C., Bannwarth, W. \& Luisi, P. L. Self-replication of oligonucleotides in reverse micelles. Helv. Chim. Acta 76, 2313-2320 (1993).

27. Bohler, C., Bannwarth, W., Luisi, P. L. \& Giustini, M. Nucleotide coupling in reverse micelles. Helv. Chim. Acta 76, 1341-1351 (1993).

28. Oberholzer, T., Wick, R., Luisi, P. L. \& Biebricher, C. K. Enzymatic RNA replication in self-reproducing vesicles-an approach to a minimal cell. Biochem. Biophys. Res. Commun. 207, 250-257 (1995).

29. Murtas, G., Kuruma, Y., Bianchini, P., Diaspro, A. \& Luisi, P. L. Protein synthesis in liposomes with a minimal set of enzymes. Biochem. Biophys. Res. Commun. 363, 12-17 (2007).

30. Kurihara, K. et al. Self-reproduction of supramolecular giant vesicles combined with the amplification of encapsulated DNA. Nat. Chem. 3, 775-781 (2011).

31. Hong, J. I., Feng, Q., Rotello, V. \& Rebek, J. Competition, cooperation, and mutation-improving a synthetic replicator by light irradiation. Science $\mathbf{2 5 5}$, 848-850 (1992).

32. Achilles, T. \& von Kiedrowski, G. A self-replicating system from 3 starting materials. Angew. Chem. Int. Ed. 32, 1198-1201 (1993).

33. Hoyle, C. H. \& Bowman, C. N. Thiol-ene click chemistry. Angew. Chem. Int. Ed. 49, 1540-1573 (2010).

34. Matsuno, R., Takami, K. \& Ishihara, K. Simple synthesis of a library of zwitterionic surfactants via Michael-type addition of methacrylate and alkane thiol compounds. Langmuir 26, 13028-13032 (2010).

35. Bachmann, P. A., Luisi, P. L. \& Lang, J. Autocatalytic self-replicating micelles as models for prebiotic structures. Nature 357, 57-59 (1992).

36. Buhse, T., Nagarajan, R., Lavabre, D. \& Micheau, J. C. Phase-transfer model for the dynamics of micellar autocatalysis". J. Phys. Chem. A 101, 3910-3917 (1997).

37. Buhse, T., Lavabre, D., Nagarajan, R. \& Micheau, J. C. Origin of autocatalysis in the biphasic alkaline hydrolysis of C-4 to C-8 ethyl alkanoates. J. Phys. Chem. A 102, 10552-10559 (1998)

38. Claridge, T. D. W. High-Resolution NMR Techniques in Organic Chemistry 398 (Elsevier Science, 2004).

39. Wong, T. C. in Encyclopedia of Surfaceand Colloid Science (ed. Somasundaran, P.) 3738-3756 (CRC Press, 2006).

40. Stilbs, P. Solubilization equilibria determined through fourier transform NMR self-diffusion measurements. J. Colloid Interface Sci. 80, 608-610 (1981).

41. Takaoka, Y., Ojida, A. \& Hamachi, I. Protein organic chemistry and applications for labeling and engineering in live-cell systems. Angew. Chem. Int Ed. Engl. 52, 4088-4106 (2013). 
42. Luisi, P. L. \& Varela, F. J. Self-replicating micelles-a chemical version of a minimal autopoietic system. Orig. Life Evol. Biosph. 19, 633-643 (1989).

43. Varela, F. J., Maturana, H. R. \& Uribe, R. Autopoiesis: the organization of living systems, its characterization and a model. Biosystems 5, 187-196 (1974).

44. Markovitch, O. \& Lancet, D. Excess mutual catalysis is required for effective evolvability. Artif. Life 18, 243-266 (2012).

45. Krężel, A. \& Bal, W. A formula for correlating pKa values determined in D2O and H2O. J. Inorg. Biochem. 98, 161-166 (2004).

46. Jerschow, A. \& Müller, N. 3D diffusion-ordered TOCSY for slowly diffusing molecules. J. Magn. Reson. Ser. A 123, 222-225 (1996).

47. Jerschow, A. \& Müller, N. Suppression of convection artifacts in stimulatedecho diffusion experiments. double-stimulated-echo experiments. J. Magn. Reson. 125, 372-375 (1997).

48. Heath, W. H. et al. Degradable cross-linkers and strippable imaging materials for step-and-flash imprint lithography. Macromolecules 41, 719-726 (2008).

\section{Acknowledgements}

We thank the EPSRC for financial support to S.P.F. (EP/H003711/1, a Career

Acceleration Fellowship) and to A.J.B. (studentship at the Systems Biology Doctoral
Training Centre at the University of Oxford) and thank Tim Claridge for help interpreting DOSY NMR experiments.

\section{Author contributions}

S.P.F. directed the research. All authors contributed towards experimental design and A.J.B performed the experiments. All authors contributed to data analysis and presentation of results. A.J.B. and S.P.F. wrote the manuscript and all authors contributed towards finalizing the paper.

\section{Additional information}

Supplementary Information accompanies this paper at http://www.nature.com/ naturecommunications

Competing financial interests: The authors declare no competing financial interests.

Reprints and permission information is available online at http://npg.nature.com/ reprintsandpermissions/

How to cite this article: Bissette, A. J. et al. Physical autocatalysis driven by a bond-forming thiol-ene reaction. Nat. Commun. 5:4607 doi: 10.1038/ncomms5607 (2014) 